\title{
Uniform Amplification of Phage with Different Growth Characteristics in Individual Compartments Consisting of Monodisperse Droplets
}

\section{Citation}

Derda, Ratmir, Sindy K. Y. Tang, and George McClelland Whitesides. 2010. "Uniform Amplification of Phage with Different Growth Characteristics in Individual Compartments Consisting of Monodisperse Droplets." Angewandte Chemie 122 (31): 5429-5432.

\section{Published Version}

doi:10.1002/ange.201001143

\section{Permanent link}

http://nrs.harvard.edu/urn-3:HUL.InstRepos:13479099

\section{Terms of Use}

This article was downloaded from Harvard University's DASH repository, and is made available under the terms and conditions applicable to Open Access Policy Articles, as set forth at http:// nrs.harvard.edu/urn-3:HUL.InstRepos:dash.current.terms-of-use\#OAP

\section{Share Your Story}

The Harvard community has made this article openly available.

Please share how this access benefits you. Submit a story.

\section{Accessibility}




\title{
Uniform Amplification of Phage with Different Growth Characteristics in Individual Compartments Consisting of Monodisperse Droplets ${ }^{*}$
}

\author{
Dr. Ratmir Derda ${ }^{\star}$, Sindy K. Y. Tang, and George M. Whitesides [Prof.] \\ Department of Chemistry and Chemical Biology, Wyss Institute for Biologically Inspired Engineering, \\ Harvard University 12 Oxford Street, Cambridge, MA 02138 (USA)
}

\section{Keywords}

competition; microfluidics; monodisperse colloids; phage-display

\begin{abstract}
Uniform amplification of a mixture of phage clones is central to the selection of peptides and proteins presented on the coat proteins of phage (phage display). [1,2] Uniform amplification cannot be achieved when phage having different rates of growth compete with each other in a common solution. Here we describe a method for uniform amplification of individual phage clones, from a mixture of clones possessing different growth characteristics. We use a microfluidic droplet generator[3] to separate individual clones from a mixture of slowly growing (S) and rapidly growing (R) M13 filamentous phage into droplets of growth media (ca. $200 \mu \mathrm{m}$ in diameter) containing E. coli. At sufficiently low concentrations of phage, each droplet contains one or no phage particles. Different phage cannot compete for bacterial hosts when isolated in different droplets, and the relative number of S and R clones present at the start is preserved after amplification. Because amplification of phage clones depends on the size of the droplets in which they reside, the use of droplets of uniform size is essential for the success of this process.
\end{abstract}

Display of random peptide sequences on the coat proteins of bacteriophages makes it possible to generate libraries of peptides of great diversity $\left(>10^{9}\right)$; rounds of selection and amplification make it possible to select peptides that bind usefully to many targets.[4-6] Modifications of phage coat proteins, however, can influence the rates of infection of bacteria, the rates of assembly of the new phage particles, or the rates of their production from infected bacteria. $[1,2]$ When phage with different compositions of the coat proteins (and thus different rates of amplification) compete for the same pool of bacteria, clones that replicate more rapidly capture an increasing fraction of the total pool of bacteria. Amplification of libraries of phage leads to selection of the clones that amplify faster than the rest of the library; [7-9] it decreases the diversity of the library and leads to loss of potentially valuable clones. For example, a library of $10^{9}$ diverse clones can contain $10^{2}-10^{3}$ of clones displaying peptides that have similar

\footnotetext{
${ }^{* *}$ We thank Dr. Lingyin Li (University of Wisconsin-Madison) for a sample of wild-type phage and Dr. Claudiu Stan for critical evaluation of the statistical models of distribution of phage in droplets. We thank Dr. Brian Hutchinson and Darren Link (Rain-Dance Technologies) for samples of fluoro surfactants and destabilizers. This work was supported by NIH ES016665, MRSEC DMR-0820484, and the Wyss Institute of Biologically Inspired Engineering. S.K.Y.T. acknowledges DARPA award W911NF-07-1-0647 for salary support. 
affinities for a target;[10] but rounds of selection and amplification are likely to retain only a few that bind to target and amplify rapidly. The problem of amplification-based selection is exacerbated when the target has many potential binding sites (e.g. cells, organs).[8,11,12] Elimination of undesired competition between different phage clones during amplification would enable selection of wider repertoire of target-binding phage independently of their relative rates of replication. We demonstrate a procedure that accomplishes this elimination.

Our demonstration used non-lytic M13 filamentous phage; this phage uses $E$. coli as a host, and produces a burst of ca. 1000 plaque-forming units (pfu) of phage within an hour of bacterial infection.[2] To model competition between phage clones, we used two sets of clones: 1) a commercially available library of M13 phage that was engineered to present a 12-mer peptide on the PIII coat protein, and 2) a wild-type (wt) phage (also known as "environmental phage"). Because wt infects bacteria more effectively than engineered phage, $w t$ is an excellent model of a "rapidly growing phage" (R), while the engineered library provides a model of a "slowly growing phage" (S). In our experiments, $S$ phage (exclusively) contained a galactosidase reporter, and formed blue plaques in bacterial colonies on solid media containing the colorimetric galactosidase substrate X-gal.[13] Reporter-free R phage forms clear plaques in the same conditions.

During growth of a mixture of $\mathrm{S}$ and $\mathrm{R}$ phage in a common suspension of E. coli (Figure 1a), the first burst of progeny from the R phage appeared sooner than that for $\mathrm{S}$ (Figure 1b). The $\mathrm{R} / \mathrm{S}$ ratio reaches $170 \pm 130 \mathrm{in}$ amplification from 50000 to $10^{11} \mathrm{pfu} \mathrm{mL}^{-1}$, and $580 \pm 380$ in amplification from 500 to $10^{11} \mathrm{pfu} \mathrm{mL}^{-1}$ (Figure 1c). In contrast, when $\mathrm{R}$ and $\mathrm{S}$ phage were amplified in separate solutions, they both reached a limiting concentration of $(3-5) \times 10^{11} \mathrm{pfu}$ $\mathrm{mL}^{-1}$, maintaining the original ratio of $1: 1$.

Polydisperse emulsions are widely used as compartments for biochemical application.[14,15] However, in amplification that proceeds to saturation (Figure 1b), different total numbers of phage are produced in compartments of different volumes. To ensure that each phage clone is amplified by the same amount, we placed them inside monodisperse droplets of growth media, generated by a microfluidic flow-focusing device (MFFD),[16-18] suspended in a

perfluorinated liquid, and stabilized by a biocompatible fluoro surfactant (Figure 2a,b).[19] We mixed phage and bacteria, and generated droplets from this mixture before the first burst of phage production occurred (within 30-45 min). Operating the MFFD at flow rates between 2-6 $\mathrm{mLh}^{-1}$, we generated $1-3 \mathrm{~mL}$ of compartmentalized phage within $30 \mathrm{~min}$, corresponding to $2 \times 10^{5}-7 \times 10^{5}$ droplets, where the droplets had an average diameter of $216 \mu \mathrm{m}(5.3 \times$ $10^{-6} \mathrm{~mL} / \mathrm{drop}$ ). This combination of carrier fluid and surfactant was critical: the stability of droplets allowed us to culture bacteria and phage by rocking the emulsions at $36^{\circ} \mathrm{C}$ in a standard Petri dish without coalescence of the drops.[20]

To demonstrate that separation of slow and fast phage in droplets eliminated competition, we used a 1:1 mixture of $\mathrm{S}$ and $\mathrm{R}$ phage at different total concentrations of phage $\left(10^{5}, 10^{4}, 10^{3}\right.$ pfu mL $\mathrm{mL}^{-1}$ ), and mixed them with $10^{8} \mathrm{cfu} \mathrm{mL} \mathrm{m}^{-1}$ of bacteria to generate droplets of $10^{-6} \mathrm{~mL}$. Each drop in this set of experiments thus contained, on average, ca. 100 bacteria and one phage (or no phage). Under these conditions, the probability that $\mathrm{S}$ and $\mathrm{R}$ phage would be present in the same droplet was small. After $7 \mathrm{~h}$ of culture, we de-stabilized the emulsions and estimated the concentration of phage in the medium using a plaque-forming assay (Supporting Information).

These experiments yielded two useful observations: 1) When amplified in droplets, the final total concentration of phage was proportional to the starting concentration of phage (Figure 2e). This observation confirmed that phage did not hop between the droplets. If phage were able to cross the fluorous phase and infect bacteria in neighboring droplets, we would expect 
the final concentration of phage in all samples to reach (3-5) $\times 10^{11} \mathrm{pfu} \mathrm{mL}^{-1}$. 2) The final R/ $S$ ratio of phage amplified in the mixture of droplets was similar to the initial ratio of ca. 1:1 $\left(2.1 \pm 1.2,1.8 \pm 0.5\right.$, and $1.6 \pm 0.3 \mathrm{pfu} \mathrm{mL}^{-1}$ for different initial concentrations Figure $\left.2 \mathrm{~d}\right)$; this ratio was not preserved in amplification of phage in bulk solution, and R/S exceeded 100:1 (Figures $2 \mathrm{~d}$ and 1c). Because phage clones do not interact, the uniform amplification should be independent of the starting R/S ratio. To test this assumption, we used mixture with high $\mathrm{R} / \mathrm{S}$ ratio. Starting from $\mathrm{R} / \mathrm{S}=(1.7 \pm 1.1) \times 10^{3}$, amplification yielded a mixture with $\mathrm{R} / \mathrm{S}$ ratio of $(3.0 \pm 2.0) \times 10^{3}$ (Supporting Information Figure S1).

We also examined how the number of phage in drops depended on the drop size. We distributed a suspension of a mixture of $\mathrm{R}$ and $\mathrm{S}$ phage (and bacteria) at a fixed concentration into emulsions made of droplets of different sizes (Figure 3a,b). Figure $3 \mathrm{~b}$ shows that, after amplification, the number of phage per droplet increased in proportion to the volume of the droplet. This relation reiterates the importance of monodispersity in droplet size. If different phage clones were isolated from each other in polydisperse emulsions, the distribution of phage amplified in this condition would mirror the polydispersity of the distribution of volumes of drops. (The volume of droplet generated by vortexing can vary by $>100$ fold.)[15]

The use of limiting dilution makes clonal distribution of phage to droplets simple. Nevertheless, it is a random process and an excess of droplets is always needed to ensure that most phage clones are placed in separate droplets. With a single droplet generator operating at $(2-5) \times$ $10^{3}$ droplets per second, the practical number of (different) phage clones that can be amplified in droplets is $10^{4}-10^{7}$ (see Supporting Information for calculations). We do not view this feature as a critical limitation: although phage screening starts from a library containing up to $10^{9}$ clones, the first round of selection typically eliminates $>99.99 \%$ of the non-binding clones. The resulting sub-library, with diversity $<10^{5}$, can readily be encapsulated and amplified in droplets. For applications that require $>10^{8}$ droplets, multiple MFFDs could be employed in parallel.[21]

In summary, our strategy allows non-competitive amplification of millions of phage clones having different growth characteristics. Use of monodisperse droplets is critical for amplifying libraries in which every clone is of different genotype: the ratio between clones can be preserved if, and only if 1) the clones are isolated from each other, and 2) all compartments have the same size. This strategy applies to any amplification process, where preferential amplification of library members is a problem (e.g. amplification of libraries of RNA enriches the sequences that amplify faster than the rest of the library).[22] Many in vitro selection procedures based on rounds of selection and amplification (e.g., phage-, ribosome-, RNA-, andDNA-display, aptamers)[23-29] can benefit from this capability. Adaptation of this strategy should be straightforward even in laboratories without microfluidics capability: the device for the generation of droplets is fairly simple;[30] microfluidics is only necessary for encapsulation, while other manipulations of phage (e.g. growth, selection) can be performed in bulk solution. If desired, however, the MFFD can be combined with other microfluidic components for onchip manipulation, quantification, and selection of drops.[31] The strategy for uniform amplification we presented here should expand the repertoire of ligands that can be identified using in vitro selection procedures.[23-29]

\section{Supplementary Material}

Refer to Web version on PubMed Central for supplementary material.

\section{References}

1. Kehoe JW, Kay BK. Chem. Rev 2005;105:4056-4072. [PubMed: 16277371]

Angew Chem Int Ed Engl. Author manuscript; available in PMC 2010 October 25. 
2. Barbas, CF., III; Burton, DR.; Scott, J.; Silverman, GJ. Phage Display: A Laboratory Manual. Cold Spring Harbor: Cold Sping Harbor Laboratory Press; 2001.

3. Garstecki P, Gitlin I, DiLuzio W, Whitesides GM, Kumacheva E, Stone HA. Appl. Phys. Lett 2004;85:2649-2651.

4. Devlin JJ, Panganiban LC, Devlin PE. Science 1990;249:404-406. [PubMed: 2143033]

5. Cwirla SE, Peters EA, Barrett RW, Dower WJ. Proc. Natl. Acad. Sci. USA 1990;87:6378-6382. [PubMed: 2201029]

6. Smith GP. Science 1985;228:1315-1317. [PubMed: 4001944]

7. Iannolo G, Minenkova O, Gonfloni S, Castagnoli L, Cesareni G. Biol. Chem 1997;378:517-521. [PubMed: 9224932]

8. Derda R, Musah S, Orner BP, Klim JR, Li L, Kiessling LL. J. Am. Chem. Soc 2010;132:1289-1295. [PubMed: 20067240]

9. Brammer LA, Bolduc B, Kass JL, Felice KM, Noren CJ, Hall MF. Anal. Biochem 2008;373:88-98. [PubMed: 17976366]

10. Rodi DJ, Makowski L, Kay BK. Curr. Opin. Chem. Biol 2002;6:92-96. [PubMed: 11827830]

11. Arap W, et al. Nat. Med 2002;8:121-127. [PubMed: 11821895]

12. Brown KC. Curr. Opin. Chem. Biol 2000;4:16-21. [PubMed: 10679380]

13. Ullmann A, Jacob F, Monod J. J. Mol. Biol 1967;24:339-343. [PubMed: 5339877]

14. Tawfik DS, Griffiths AD. Nat. Biotechnol 1998;16:652-656. [PubMed: 9661199]

15. Griffiths AD, Tawfik DS. Trends Biotechnol 2006;24:395-402. [PubMed: 16843558]

16. Anna SL, Bontoux N, Stone HA. Appl. Phys. Lett 2003;82:364-366.

17. Gañán-Calvo AM, Gordillo JM. Phys. Rev. Lett 2001;87:274501. [PubMed: 11800883]

18. Garstecki P, Stone HA, Whitesides GM. Phys. Rev. Lett 2005;94:164501. [PubMed: 15904231]

19. Holtze C, et al. Lab Chip 2008;8:1632-1639. [PubMed: 18813384]

20. Droplets ranging from $5 \times 10^{-8} \mathrm{~mL}$ (diameter ca. $40 \mu \mathrm{m}$ ) to $5 \times 10^{-5} \mathrm{~mL}$ (diameter ca. $670 \mu \mathrm{m}$ ) are suitable for this approach. We observed that the droplets of diameter $<40 \mu \mathrm{m}$ could support growth of only a few bacteria and are not practical for amplification of phage. Drops $>500 \mu \mathrm{m}$ were unstable and susceptible to disruption into smaller drops by shear during incubation or rocking. Droplets that coalesce upon collision were previously used to isolate bacteria; but these drops must be cultured inside tubing. Culture of a typical number of droplets we used in most experiments $\left(3 \times 10^{5}\right)$ would require $>90 \mathrm{~m}$ of tubing (for $200 \mu \mathrm{m}$ drops separated by a $100 \mu \mathrm{m}$ plug of carrier fluid) and would not be practical.

21. Li W, Young EWK, Seo M, Nie Z, Garstecki P, Simmons CA, Kumacheva E. Soft Matter 2008;4:258262.

22. Breaker RR, Joyce GF. Proc. Natl. Acad. Sci. USA 1994;91:6093-6097. [PubMed: 7517040]

23. Halpin DR, Harbury PB. PLoS Biol 2004;2:1022-1030.

24. Yonezawa M, Doi N, Kawahashi Y, Higashinakagawa T, Yanagawa H. Nucleic Acids Res 2003;31:e118. [PubMed: 14500846]

25. Wittrup KD. Curr. Opin. Biotechnol 2001;12:395-399. [PubMed: 11551469]

26. Amstutz P, Forrer P, Zahnd C, Pluckthun A. Curr. Opin. Biotechnol 2001;12:400-405. [PubMed: 11551470]

27. Hanes J, Plückthun A. Proc. Natl. Acad. Sci. USA 1997;94:4937-4942. [PubMed: 9144168]

28. Boder ET, Wittrup KD. Nat. Biotechnol 1997;15:553-557. [PubMed: 9181578]

29. Brekke OH, Loset GA. Curr. Opin. Pharmacol 2003;3:544-550. [PubMed: 14559101]

30. The system we used required minimal peripheral equipment (two syringe pumps and a camera to monitor droplet generation). This setup can be further simplified using hydrostatic pressure to drive the flow.

31. Clausell-Tormos J, et al. Chem. Biol 2008;15:427-437. [PubMed: 18482695] 


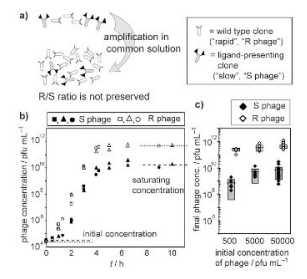

Figure 1.

a) Amplification of two types of phage in the same solution. Clones that grow faster are enriched during the amplification. b) Time-dependence of concentration of $\mathrm{S}$ and $\mathrm{R}$ phage that compete for the bacteria host in the same solution; c) We mixed $500+500,5000+5000$ or $50000+$ 50000 pfu of S and R phage, added bacteria, and measured the concentration of S and R after $7 \mathrm{~h}$ of amplification. Panels (b) and (c) present all data (3-5 experiments); the overlaying grey bar is equal to $2 \times$ (standard deviation). 


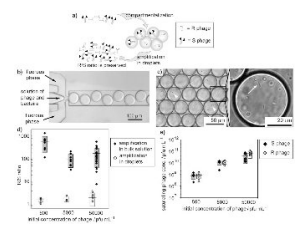

Figure 2.

a) Isolation of phage in separate droplets that contained bacteria eliminates competition during amplification. b) Images of droplets generated in a MFFD. c) Images of bacteria (arrow heads) and dividing bacteria (arrow) in a droplet. d) $\mathrm{R} / \mathrm{S}$ ratio obtained by amplification of a 1:1 mixture of $\mathrm{R}$ and $\mathrm{S}$ phage in bulk solution or in droplets. We compared the number of phage obtained by amplification of phage at different initial concentrations. e) The final concentrations of $\mathrm{R}$ and $\mathrm{S}$ were proportional to the initial numbers of $\mathrm{R}$ and $\mathrm{S}$ phage. (Figure $\mathrm{d}$ and e present all data (i.e., no selection; $2-5$ experiments); the overlaying grey bar is equal to $2 \times$ (standard deviation)). 


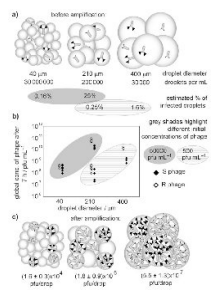

Figure 3.

a) We compared amplification of 1:1 mixtures of S and R phage of the same concentrations placed in droplets of different sizes. Estimated \% of infected droplets = (initial concentration of phage, pfu mL $\left.{ }^{-1}\right) /($ number of droplets per $\mathrm{mL})$. b) For the same initial concentration of phage, increase in droplet size led to higher concentration of phage after amplification $(N=2-$ 4). c) The number of phage per drop after amplification was estimated as (final concentration of phage, pfu $\left.\mathrm{mL}^{-1}\right) /($ number of infected droplets per $\mathrm{mL}$ ). 